\title{
PROFISSIONALIZAR A ADMINISTRAÇÃO DA CULTURA
}

José Carlos Garcia Durand

E-mail cecc@eaesp.fgvsp.br

Professor do Departamento de Fundamentos Sociais e Jurídicos da Administração e Coordenador do Centro de Estudos da Cultura e do Consumo da EAESP/FGV.

RESUMO: Após enunciar os principios que devem nortear uma gestāo cultural moderna e democrática, o artigo traça um panorama da área cultural pública brasileira entre 1986 e 1994. Examina o descaso de políticos, os critérios duvidosos na escolha de dirigentes de cúpula e a falta de qualificação de seus técnicos. Fornece pistas de como fazer avançar a racionalidade administrativa indispensável para que o Estado e empresas possam engajar-se em parcerias, como acontece na maioria dos paises avançados.

ABSTRACT: Four principles seem to sum up what one might expect of an efficient and democratic cultural policy: quality, diversity, preservation of identities and dissemination of values. To achieve these objectives, a minimum of political and administrative continuity is necessary; a minimum of professionalization should be offered for the technical and concerned directing personnel. The article examines main challenges to the modernization cultural policy, in Brazil, since the end of military regime (7986) until nowadays.

PALAVRAS-CHAVE: administração cultural, administraçāo pública, política cultural, profissionalismo.

KFYWORDS: culture management, public administration, cultural policy, professionalization. 
Aos gestores culturais cabe dar clareza, coerência e eficácia à formulação de objetivos, programas e projetos em matéria de cultura, no espaço público ou privado. Mas é forçoso reconhecer que nesse assunto a situação dos países sul-americanos não é das mais avançadas. Se for possível considerar como geral o caso do Brasil, será lícito constatar que - com as exceções de sempre - os governantes (seja no nível federal, regional ou local) não costumam encarar a gestão cultural como esfera onde se exijam aquelas virtudes. É, portanto, muito oportuno este evento.

Correlatamente à falta de clareza e coerência, e à despreocupação com eficácia, os recursos são ao mesmo tempo escassos e mal aproveitados. Com freqüência, a fatia da cultura fica muito abaixo do $1 \%$ dos orçamentos públicos, tal como parece ser considerada a participação mínima razoável do setor na despesa governamental. Por sua vez, os recursos privados continuam difíceis de chegarem aos produtores culturais, apesar das leis de incentivo à cultura que começam a ser postas em prática ${ }^{1}$. Os interesses corporativos dos artistas costumam ser fortes na disputa pelas migalhas oferecidas pelos governos, enquanto os interesses dos políticos costumam ser tão fracos que dificilmente o tema cultura aparece em programas de partidos políticos ou em plataformas de candidatos a postos eletivos. Aliás, no Brasil, mesmo a educação só agora começa a ocupar o lugar que merece no discurso político.

Prevalece, de modo geral, enorme perplexidade a respeito de como tratar esse delicado tema. Estamos em uma época em que as definições de cultura proliferaram até o paroxismo, contando-se às centenas. Por um lado, elas se impregnaram das mais diversas significações libertárias, em nome da preservação da identidade das mais variadas minorias e de tudo quanto pareça atitude progressista. Por outro lado, como efeito final de décadas e décadas de "rupturas" promovidas pelas vanguardas em quase todos os segmentos artísticos, ultrapassou-se o limite mínimo de consenso quanto ao que seja valor estético. Tudo pode ser arte e nada é arte. O que dizer de uma época em que se considera normal que, num museu, um visitante pare dian-

te de um quadro e, em vez de instantaneamente exclamar "que belo!", ou "que horrivel!" - como faria se tomado de forte e incontrolável emoção visual -, silencie e balbucie, meio constrangido, "interessante..."? Tudo se passa como se a obra de arte lá estivesse para servir à curiosidade, à decifração ou à especulação intelectual, como os enigmas ou as hipóteses científicas.

\section{Quatro princípios parecem resumir o que se pode esperar de uma política cultural democrática e eficiente: qualidade, diversidade, preservação de identidades e disseminação de valores.}

O painel até aqui esboçado associa certamente alguns componentes particulares ao Brasil, outros que são comuns aos países da América do Sul e ainda aqueles que são expressão de tendências mundiais. Não há espaço, nem talvez haja necessidade, de se definir o alcance geográfico $e$ social de cada um; o mais importante talvez seja encarar com coragem o que ainda pode ser definido como base de uma política cultural desejável.

\section{FUNDAMENTOS DE POLÍTICA CULTURAL}

Quatro princípios parecem resumir o que se pode esperar de uma política cultural democrática e eficiente: qualidade, diversidade, preservação de identidades e disseminação de valores ${ }^{2}$. Ou seja, que, no intuito de estimular atividades culturais, o Estado - sem jamais se tornar ele próprio produtor de cultura - ajude a assegurar um fluxo de bens e atividades culturais com qualidade (estética ou científica, conforme se trate de cultura artística ou científica). Que esse fluxo comporte diversidade suficiente para oferecer ao cidadão reais opções de consumo cultural entre os segmentos artísticos, e em cada um destes. Que a cultura possa ser o território em que se afirmem e reafirmem identidades particulares (nacionais, regionais, étnicas, sexuais, etárias, religiosas etc.), em contraposição à força globalizadora da in-
Artigo apresentado no II Encuentro Internacional sobre Formación en Gestión Cultural, organizado pelo Convenio Andrés Bello, pela Subsecretaría de Cultura del Ministerio de la Educación y Cultura del Ecuador, e pela Organización de Los Estados Iberoamericanos. Quito, 2428 de julho de 1995.

1. No Brasil, as leis de incentivo à cultura em vigor conseguem repassar efetivamente apenas entre 10 e $50 \%$ dos recursos colocados à disposição pelas empresas, por razōes variadas. Estas abrangem desde a dificuldade de se encontrarem projetos em condiçōes técnicas de serem aprovados, e também, de se montarem comissōes de avaliação, até a necessidade de se encontrarem empresas dispostas a acrescentarem uma parcela de recursos próprios àquela dos impostos que deixam de recolher.

2. Elementos apresentados oralmente por Zarko Paic, da Open University da Croácia, em uma comunicação sob o tema "Postmodernism and cultural policy", feita na First World Culturelink Conference, ocorrida em Zagreb, Croácia, de 8 a 11 de junho de 1995. Ver também, a respeito: CHAUÍ, Marilena. Cidadania cultural como diretriz, Informativo do Instituto de Estudos Avançados da USP, p. 7, mar. 1995. 
Por sua vez, a vontade política de fazer a

cultura florescer em clima democrático e

plural tem dois pré-requisitos

institucionais. Primeiro, que haja um

mínimo de continuidade político-

administrativa; segundo, que se ofereça

um mínimo de profissionalização a técnicos

e a dirigentes da área. (o grande escritor, o filólogo de renome ou o compositor de sucesso).

Mulheres podem ser tão capazes quanto homens para administrar cultura, assim como o são em quaisquer outras áreas, não há a menor dúvida a respeito. Todavia, questão diversa é se considerar, como fazem ainda alguns setores atrasados de nossas elites políticas e econômicas, que cabe a mulheres de políticos encarregarse de cultura, simplesmente porque os costumes de sua classe social colocam cultura no elenco das virtudes femininas. Pode até ser que a esposa deste ou daquele político seja pessoa de grande descortino na área cultural, e aí sua escolha não será pela condição de sexo nem pela relação de parentesco.

Por outro lado, muitos têm sido nomeados em cargos de ministro ou de secretário de cultura simplesmente porque são artistas ou intelectuais de grande expressão. Os governantes que os escolheram o fizeram para "dar brilho" a uma equipe de governo ou "impor-se" perante a comunidade artística. Aliás, às vezes, nem é apenas uma questão de extremo brilho do escolhido, mas, antes, de algum prestígio cultural associado, quem sabe, à condição de vítima de um regime autoritário. Nomear como ministro ou secretário de cultura um ex-perseguido político é uma tentativa, talvez meritória, de reparar prejuízos causados por uma ditadura junto à comunidade artística ecientífica. Mas pode redundar num fracasso, do ponto de vista administrativo.

Experiências têm mostrado que dirigentes escolhidos pelo critério da consagração cultural costumam chegar idosos demais aos postos decisórios. Além de não raro - não estarem acostumados a trabalhar em equipe e nem a suportar processos de negociação, geralmente usam do posto executivo para realizar antigos caprichos e projetos pessoais, que podem acabar se sobrepondo às prioridades reclamadas pela eficiência, pelo bom senso e por uma objetividade não afetada pelo narcisismo. Quando não, esse tipo de dirigente cultural costuma precocemente "deixar de gostar" do poder e, quando menos se espera, já entregou a responsabilidade do cargo a um subordinado e retornou solitário e feliz a seus ensaios críticos, à preparação de seus dicionários ou o que quer 
que seja. Em suma, a direção da área pública de cultura não deve ser concedida a alguém como honraria por desempenho intelectual e artístico, nem como reparação ético-política, e muito menos como prêmio de consolação a quem não pôde ser contemplado com posto elevado em outra área de governo mais compatível com suas aptidões.

Outra mazela da vida política de alguns países, e que se reflete agudamente no setor cultural, é o excessivo número de "cargos de confiança" preenchido após cada mudança de governo. No Brasil, no conjunto da administração pública federal, estima-se que o número de dirigentes $\mathrm{e}$ assessores trocados após cada eleição seja 15 ou 20 vezes superior ao de um país desenvolvido, como a França ou os Estados Unidos. Se tal descontinuidade é capaz de prejudicar qualquer esfera da administração, mesmo aquelas onde existe mais dinheiro e mais clareza de ação governamental, imagine-se a devastação que pode fazer em uma área como a cultura, na qual os poucos e mal-pagos técnicos do governo têm, em geral, somente uma formação autodidata $^{3}$.

\section{PROFISSIONALISMO NA ÁREA CULTURAL}

Pelo visto, entre os progressos ainda por se instalarem na área cultural pública de alguns dos países está o que se refere a critérios de escolha de seus dirigentes superiores. É preciso evitar o clientelismo; é preciso desconfiar de tentativas (às vezes puramente ilusórias) de valorização da área cultural pela elevação de seu nível no conjunto da administração. A propósito, comenta-se no Brasil que, nos anos 80, a passagem da Cultura do nível de Secretaria do Ministério da Educação à condição de Ministério autônomo teria sido antes um subterfúgio para o então Presidente da República, José Sarney, aumentar o espaço de ação de um aliado político, do que propriamente a ampliação de poder institucional necessária para expandir e melhorar essa esfera de ação. Em conseqüência, não são raros os que avaliam que a situação no Brasil era melhor quando a administração federal da cultura era vinculada à da educação.

Fazer avançar o profissionalismo nos níveis técnicos intermediários da adminis- tração pública da cultura não é, em princípio, uma tarefa muito difícil. Por um lado, a maioria dos países dispõe de um número suficiente de escolas de administração pública e de negócios, de faculdades de comunicações e artes e de outros tantos ramos de ensino que podem qualificar pessoal para a gestão da cultura. Bastaria o desenvolvimento de programas de reciclagem e ajustes e complementações em currículos universitários. Por outro lado, na maior parte dos países da América do Sul já existe um estoque suficientemente grande de pessoas com escolarização elevada, capaz de formar mercado para gêneros culturais mais sofisticados $^{4}$. As empresas - ao menos as do círculo das maiores corporações econômicas privadas - começam, timidamente ou não, a apoiar iniciativas culturais, e isso desperta a atenção para os dividendos (sobre a imagem da empresa e seus produtos) que o apoio às artes pode oferecer ${ }^{5}$, enfim, como algo que pode ser encarado da perspectiva do lucro e melhorado pelo uso de técnicas modernas de administração. Pouco a pouco vão surgindo os profissionais que farão a necessária ponte entre empresas e cultura, e que ajudarão no preparo e manejo de leis de incentivo fiscal, no estabelecimento de programas de estímulo ao mecenato particular e em seminários e debates sobre os ganhos possíveis das empresas com o patrocínio à cultura.

Seguramente é muito mais fácil transmitir técnicas de administração a gestores culturais e ensiná-los a formular, acompanhar e controlar a execução de projetos do que conciliar os princípios que fundamentam uma política cultural: qualidade, diversidade, preservação de identidades e disseminação de valores positivos. Melhor dizendo, a questão-chave para a formação de agentes culturais capazes de definir e implantar diretrizes de política pública está em sua formação teórica. Cabe então
3. Embora se trate de um mandato presidencial atípico, posto que terminado pelo vice-presidente, em virtude do impeachment do presidente eleito, o governo Fernando Collor/ltamar Franco (março de $1990 /$ dezembro de 1994) teve nada menos do que cinco ministros da cultura, cada um com perfil diverso do anterior. Vale citar também a situação com que se defrontou 0 atual governo do Estado de São Paulo, iniciado em janeiro de 1995, quando constatou na administração um número enorme de funcionários contratados irregularmente. Ou seja, contratados à margem da lei, por meio de uma empresa estatal de prestação de serviços chamada Baneser, filiada ao Banco do Estado de São Paulo. $\mathrm{Na}$ Secretaria Estadual de Cultura, apurou-se que 1.500 de seus 2.000 funcionários estavam nessa situação e acabaram sendo demitidos. Destes, 400 foram reaproveitados de modo precário, por meio da lei $n^{2} 3.131$, que obriga 0 Governo a renovar seus contratos trimestralmente. Nessa mudança, eles perderam mais da metade da remuneração que auferiam. Com tamanho corte, a programaçẫo da Secretaria teve que ser reduzida, mas se procurou intensificar parcerias com empresas para evitar cancelamento de programas.

4. Estima-se esse estoque em três milhóes de pessoas, no Brasil.

5. DURAND, J. C. Business and culture in Brazil. In: MARTORELLA, Rosanne (org.). Business and culture: a global perspective, New York : Praeger (no prelo); MENDONÇA, Marcos. A delicada fronteira entre empresa e cultura. In: MENDONÇA, Marcos (org.). Lei de incentivo à cultura - uma saída para a arte. Săo Paulo: Carthago \& Forte, 1994, p. 31-9.
Fazer avançar o profissionalismo nos níveis técnicos intermediários da administração pública da cultura não é, em princípio, uma tarefa muito dificil. 
6. Dois estudos esclarecem muito bem isso: VERGER, Annie. L'art d'estimer l'art - comment classer 'incomparable? Actes de la Recherche en Sciences Sociales Paris, n. 66/67, mar.1987; CRANE, Diana. Avant-garde art and social change: the New York art world and the transformation of the reward system, 1940-1980. In: MOULIN, Raymonde (org.). Sociologie de l'art. Paris : La Documentation Française, 1986.

7. HUGHES, Robert Cultura da reclamaçáo: o desgaste americano. São Paulo: Cia. das Letras, 1993.

8. Ou, segundo a sugestiva mencão de um artista plástico, ouvida em entrevista: "Hoje em dia, 'para frente' pode ser para qualquer lado, inclusive para trás".

9. A rede de agências de financiamento à ciência mantidas pelo governo federal e por alguns governos estaduais no Brasil é considerada bastante satisfatória. Ela assegura a um número grande de professores e pesquisadores brasileiros oportunidade de se titularem e de se reciclarem dentro $e$ fora do país. Todavia, é um sistema em que os cientistas têm autonomia plena para decidir o que deve ou nấo ser financiado.

10. É absolutamente necessário que o gestor cultural conheça as funcões cumpridas pela indústria cultural nos sistemas culturais das sociedades complexas, como única saída para evitar que ele $\mathrm{S}$ confine na retórica conservadora e equivocada que tende a somente ver, na cultura de massa, mediocridade e estereotipação.

11. DONNAT, COGNEAU. Les pratiques culturelles des Français, 1973-1989. Paris: La Découverte/ La Documentation Française, 1990.

12. CANCLINI, Néstor García. Cutturas hibridas: estratégias para entrar y salir de la modernidad. Mexico: Consejo Nacional para la Cultura y las Artes, 1990

13. Esta constatação é recente, mas a obsolescência de um megaevento como a Bienal Internacional de Artes Plásticas de São Paulo já vem sendo indicada faz um bom tempo. Ver, a respeito, a publicaçăo a seguir, onde onde 0 autor imagina, com bom humor, as múltiplas atividades culturais que poderiam usar melhor a imensa área ocupada pela Bienal: KLINTOWITZ, Jacob. 30 segundos de televisão valem mais do que dois meses de Bienal de São Paulo: isso é bom ou ruim? São Paulo: Summus, 1981. perguntar: de quais recursos teóricos exatamente ele vai precisar para ter visão adequada desses princípios e, sobretudo, das condições para a conversão desses princípios em programação?

Algumas perguntas que costumam emergir em debates acerca de cultura e administração cultural, ou que despontam em ensaios críticos das mais variadas inspirações teóricas e nos mais diferentes países, servem para dar uma idéia da complexidade dos processos culturais contemporâneos e da necessidade de se entendêlos corretamente.

Por exemplo, o que define exatamente qualidade em termos de produção artísti$c a$, quando se sabe que em certos gêneros "nobres", como as artes plásticas, a mercantilização hoje imperante no circuito das mostras internacionais e das galerias particulares indica que quase não existe mais juízo estético isento de interesse econômico ${ }^{6}$ ? O que define qualidade propriamente estética se uma obra qualquer pode reivindicar existência simplesmente por veicular uma mensagem tida por politicamente correta, como ironicamente tem apontado Robert Hughes 7 ? O que é mais importante para fazer florescer um segmento artístico qualquer em uma localidade determinada: fomentar a produção local ou exibir aos artistas locais o que se faz fora? Uma produção de "fora" significa aquilo que é feito em um grande centro no próprio país em que se está ou que é feito em alguma capital cultural internacional extra-fronteiras? E como decidir o que é uma capital cultural internacional se elas hoje são múltiplas e se distribuem em vários países ${ }^{8}$ ? Em suma, essas questões sugerem o quanto é difícil importar cultura de qualidade atualmente.

O que é prioritário: formar praticantes ou montar acervos? Proteger o patrimônio ou fomentar eventos? Como conciliar o que os pequenos círculos de produtores culturais acreditam que se deva fazer com aquilo em que os cidadãos (por definição, a população a ser contemplada pela política cultural) estejam mais interessados? $O$ modo de operação corporativa do financiamento público à ciência pode ou não ser estendido às artes? $\mathrm{E}$ com que conseqüências ${ }^{9}$ ? Como avaliar o papel da indústria cultural no conjunto da cultura de um país, quando se sabe que ela recicla, ampliando o consumo, obras originárias da cultura erudita e da cultura popular? Ou quando se sabe que ela promove com muita facilidade uma nefasta massificação ${ }^{10}$ ? Como definir política cultural e dispêndio público em cultura, quando a meta básica do governo é gerar empregos, como ocorre hoje na França? O que fazer ou deixar de fazer quando se sabe que, nos últimos vinte anos, os novos aparelhos eletrônicos, ao multiplicar as possibilidades de desfrute cultural a domicílio, vem afetando mais o consumo cultural coletivo do que os vastos orçamentos públicos e privados utilizados, nos países ricos, para levar mais pessoas a práticas de cultura de elite em recinto aberto, como museus, teatros e salas de concerto ${ }^{11}$ ? O que fazer ou deixar de fazer diante do desencanto e da nostalgia - tal como sentiu Néstor García Canclini - de ver, entre descendentes de povos pré-colombianos que esculpem há séculos imagens ancestrais, felizes artesãos integrados ao mercado, satisfeitos por falar em espanhol e em inglês com os turistas e por esculpir objetos inspirados em peças de arte moderna de museus de New York ${ }^{12}$ ? Depois de tanto criticar o desinteresse do público pela cultura de elite em nosso continente, como explicar que uma exposição itinerante, como a do escultor Rodin, atraia quatro ou cinco mil pessoas por dia em São Paulo ou no Rio de Janeiro? Se as exposições bienais internacionais de artes plásticas existem, como o nome indica, para mostrar os avanços mais recentes da arte, como entender que os visitantes quase só se interessem pelas salas onde estão as retrospectivas de artistas falecidos há muito tempo ${ }^{13}$ ? As respostas a essas e outras tantas questões certamente não são simples, mas o agente cultural deve ter pelo menos noção dos caminhos por onde passam as explicações para processos tão instigantes. Para isso, é preciso pensar em teoria e tentar convertê-la em diretriz de ensino ${ }^{14}$.

\section{OS EIXOS TEÓRICOS DE FORMAÇÃO DO AGENTE CULTURAL}

Um profissional para atuar na definição de prioridades, no desenho e no acompanhamento de projetos culturais, em conta- 
to simultâneo com autores e artistas, com outros intermediários (eventualmente com patrocinadores privados) e também com o destinatário final da cultura, é alguém que precisa ter formação sólida e espírito versátil ${ }^{15}$.

É preciso que ele entenda, antes de tudo, a lógica da cultura em sociedades complexas, ou seja, em sociedades nas quais coexistam cultura de elite, indústria cultural e cultura popular. Está aí incluída a capacidade de analisar, sem ingenuidade nem preconceitos, a lógica econômica de cada um desses três domínios e os rendimentos econômico, de prestígio e de popularidade que em cada um deles seja possível obter.

Mas é preciso também um mínimo de entendimento dos regimes políticos e das relações entre Estado e cultura, pois só assim ele saberá quais são as modalidades de intervenção que o Estado pode fazer na área de cultura. Só assim ele poderá ter noção segura dos condicionantes políticos e institucionais para uma administração eficiente, no contexto de uma política cultural efetivamente democrática.

Finalmente, o conhecimento da lógica da concorrência entre empresas e dos fundamentos das estratégias de médio e longo prazos adotadas pelas grandes corporações é um requisito para o adequado entendimento da razão de ser, do alcance e dos limites do patrocínio privado à cultura. Conhecendo esse alcance e esses limites, o agente cultural tenderá a moderar seu otimismo quanto à crença neoliberal na eficiência do mercado para o apoio da cultura, e assim respeitará melhor o território e as atividades que precisam ficar ao encargo do Estado.

\section{OS EIXOS PRÁTICOS DA FORMAÇÃO DO AGENTE CULTURAL}

É indispensável ao agente cultural a capacidade de perceber que, em termos das leis da economia, os bens culturais são diferentes dos bens econômicos em geral, e, em conseqüência, que o marketing cultural não é uma extensão pura e simples do marketing que faz vender sabonetes ou automóveis ${ }^{16}$.

Da informática podem ser retirados recursos sem fim para simplificar o preparo, o orçamento e o acompanhamento de pro-

É indispensável ao agente cultural a

capacidade de perceber que, em termos

das leis da economia, os bens culturais são

diferentes dos bens econômicos.

jetos. Os computadores também permitem simplificar pesquisas que retratem mais rapidamente o perfil e os hábitos do consumidor cultural.

Direitos culturais, direito de autor, incentivos fiscais à cultura e proteção do patrimônio, entre outros, também são ferramentas que o agente cultural não pode desconhecer.

Finalmente, como cada gênero cultural tem sua história particular em cada país, é importante que o agente cultural tenha noção de seu desenvolvimento ao longo do tempo. Daí a importância de lhe serem oferecidos "diagnósticos setoriais" - por exemplo, o estado geral das artes plásticas, das artes cênicas, da música, em determinado país ou região. Os estudos de caso - ferramenta de utilidade mundialmente reconhecida no ensino da Administração - ajudam a treinar o profissional diante de situações concretas, aumentando sua capacidade de decisão.

Em síntese, para bem exercer seu ofício, o agente cultural deve conhecer o que sua época oferece como possibilidades de entendimento do campo da cultura e como recursos administrativos. Para isso, seguramente ele precisa despojar-se de receios impostos por ideologias de origens variadas. Por exemplo, precisa deixar de crer que o Estado pode tudo fazer ou tudo delegar à iniciativa privada em termos de cultura. Deve aceitar que analisar a cultura do ponto de vista econômico não é uma forma de violentá-la, mas, antes, de poder geri-la melhor. Não pode ser ingênuo a ponto de acreditar que tudo o que os países desenvolvidos oferecem sob o rótulo de vanguarda merece respeito indiscutível, como se esse conceito estivesse acima de qualquer suspeita. Sobretudo, não pode achar que cultura é o território do desinteresse, como ainda tentam fazer crer ideologias sustentadas por quem é muito rico ou por quem trabalha para passar fome e faz disso virtude ${ }^{17}$.
14. As considerações que seguem resultam da experiência apurada nas aulas e debates ocorridos desde 1994, no Curso de Administração da Cultura, organizado pelo CECC na EAESP/ FGV, embora a responsabilidade deste artigo seja só do autor. Para uma descrição desse programa de ensino, ver: DURAND, J.C. Lazer, cultura e profissăo. In: MARCELLINO, Nelson C. (org.). Lazer: formação e atuação profissional. Campinas: Papirus, 1995, p. 55-62. (Coleçāo Lazer \& Fazer).

15. As disposiçōes pessoais que permitem definir aptidão para animador cultural (e, por extensão, a todo tipo de gestor cultural) estăo muito bem apresentadas nestes dois textos de um mesmo autor: GARCIA, Erivelto Bust. Os novos militantes culturais. In: MARCELLINO, Nelson C. Op. cit.,

p. 23-54; Radicais, conformistas e alternativos: aspectos da política de recursos humanos para o lazer do SESC de Săo Paulo. In: MARCELLINO, Nelson C. Op. cit, p. 135-48.

16. COLBERT, François. Le marketing des artes et de la culture. Boucherville, Québec: Gaëtan Morin, 1993.

17. Para uma descrição das formas de manifestação da "ideologia do desinteresse", assim como de suas funçōes e conseqüências da glorificaçăo da miséria económica no campo artístico, ver: BORDIEU, Pierre. 0 mercado de bens simbólicos. In: MICELI, Sergio (org.). A economia das trocas simbolicas. S. Paulo: Perspectiva, 1974. 